\title{
Vision improvement with low vision aids and functional vision assessment among children studying in schools for the blind in North-East India
}

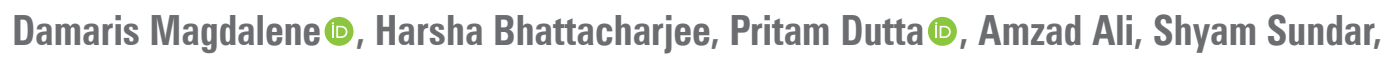 \\ Ram Mohan Paidi \\ Sri Sankaradeva Nethralaya, Guwahati-Assam, India
}

\begin{abstract}
BACKGROUND: The study aimed to assess the vision improvement with low vision aids (LVA) and functional vision among children learning in schools for the blind in North-East India.

MATERIAL AND METHODS: 515 students from 17 blind schools of North-East India were recruited. The comprehensive ocular examination, functional vision assessment, and vision assessment using LVA were carried out for all the subjects after determining the magnification required for each subject.

RESULTS: Of 515 children, 124 required LVA. Spectacle magnifiers were the most preferred ( 73 students, 58.87\%), followed by magnifiers (50 students, $40.32 \%$ ). A statistically significant improvement in the mean visual acuity was noted after the use of LVA $(\mathrm{p}<0.001)$.

CONCLUSION: A detailed assessment of low vision prior to admission to schools should be made mandatory in blind schools. These schools would be able to cater to really blind children, while children with low vision could attend regular schools.
\end{abstract}

KEY WORDS: blind school; low vision aids; functional vision

Ophthalmol J 2021; Vol. 6, 72-75

\section{INTRODUCTION}

World Health Organization (WHO) originally defined low vision as visual acuity less than $20 / 60$ to $10 / 120$ in the better eye. However, it was found that children who have a corrected visual acuity in the better eye of less than 10/200 have a good residual vision, and low-vision services are found beneficial for them. In 1992 at a WHO consultation meeting, a revised "working definition" of low vision was agreed upon [1]. As per the revised definition, a person with low vision is defined as someone who has a corrected visual acuity of $20 / 60$ to light perception in the better eye or a visual field of less than $10^{\circ}$ from the point of fixation after full optical correction and surgical treatment, but who uses or has the potential to use vision for the planning and/or execution of the task. A considerable proportion of students in schools for the blind receive formal training using Braille. However, there is a growing recogni-

CORRESPONDING AUTHOR:

Dr. Damaris Magdalene, Sri Sankaradeva Nethralaya, 96, Basistha Road, Beltola Tiniali, Guwahati, Assam 781028 India, tel: 9864018956; e-mail: drmaggie01@gmail.com 
tion of the need for print education for children with limited vision. Low-vision rehabilitation entails offering assistive devices and training to patients to enhance their quality of life [2]. This study was designed to assess the benefits of low vision aids and functional vision improvement among children studying in schools for the blind in North-East India.

\section{MATERIAL AND METHODS}

This is a descriptive, interventional, cross-sectional study. The study was approved by the Institutional Review Board and adhered to the tenets of the Declaration of Helsinki.

There are 17 schools for the blind in eight states of North-East India. The schools were identified with the help of blindness control societies of each state. The required permission for the screening of the children was obtained from the principal of each school. The principals were briefed about the aims and objectives of the study. The school authorities were also requested to inform the parents of the children at the time of screening. The detailed methodology of the study is as follows:

- the children's medical records were reviewed, and an ocular examination was performed using a torchlight, a handheld slit lamp, and ophthalmoscopy. Retinoscopy and visual acuity estimation, and low vision evaluation were also performed and recorded using WHO's eye examination protocol [3]. Children were examined with/without spectacles/and with low vision aids (LVA). The log MAR chart was used to measure distance vision at a distance of $4 \mathrm{~m}$ from the patient. To test near vision, a reduced Snellen's chart was employed;

- "functional vision" was based on the ability to accomplish the following four tasks:

a) test of independent mobility (potential to move between two chairs set two meters apart in a well-lit room without assistance),

b) test of social contact (ability to identify someone at a distance of 10 feet),

c) test of near vision (capacity to comprehend the contour of three $2-\mathrm{cm}$ symbols at any close distance approximately equal to N-60),

d) useful residual vision (if formal testing of visual acuity is not possible, sufficient vision was defined as the ability to move around independently, make social interactions, or see objects up close);
- hand-held slit-lamp examination of the anterior segment and indirect ophthalmoscopy for the posterior segment were performed. The primary defect that caused the child's vision loss was also noted. The Heine Beta 200 R Retinoscope was used to perform objective refraction. Objective refraction test was performed with the aid of a trial frame and refraction set on a log MAR chart in sufficient light;

- reduced Snellen's charts were employed to assess near vision under appropriate room lighting. For near acuity testing, the M-unit is the ideal approach. The M-unit is the only well-defined letter size unit. At 1 meter, a $1 \mathrm{M}$ letter represents 5 minutes of arc. A $1 \mathrm{M}$-sized letter is the same size as a newspaper $(\mathrm{N} 8=1 \mathrm{M})$ for comparison purposes. $2 \mathrm{M}$ is the size of a regular 18 point large print, while $0.5 \mathrm{M}$ is the size of a print half the size of a newsprint.

- the examination room and the charts were illuminated correctly during the LVA assessment in all the schools. For those unaided distance or near visual acuity was tested, an approximate requirement of LVA for near was calculated. The following formula was used to calculate LVA for the near:

\section{Magnification required $=$ present visual acuity/ Irequired visual acuity}

The examination of LVA was performed binocularly and monocularly according to the visual performance of the child. For the LVA test, we employed a $5 \times$ and $7.5 \times$ illuminated stand magnifier, a $2.5 \times$ and $7.5 \times$ non-illuminated stand magnifier, a bar magnifier, a handheld magnifier of 20 dioptres (D), 30D, and 35D, and spot magnifiers of 24D, $32 \mathrm{D}$, and $40 \times$. For the eye with better vision, LVA was prescribed. As a result, a copy of each child's medical record was supplied to their school and coordinators, allowing the authority to take the appropriate measures to distribute the LVAs.

\section{STATISTICAL ANALYSIS}

Using Microsoft Excel and SPSS software, all of the collected data was statistically analyzed. Mean (SD), and percentages were used to describe the descriptive parameters. Frequency distribution was calculated for the number of subjects and line improvement in visual acuity. Paired t-test was used to compare the visual acuity with and without LVA. 


\section{RESULTS}

Of the total examined 515 children, 124 children required low vision aids. All the children were between 6 to 18 years age group. There were 73 males and 51 females who needed low vision aids. The diagnosis of the patients who benefited from LVA is presented in Table 1 . There was a statistically significant line improvement in the near vision chart noted for the entire patient $(\mathrm{p}=0.048)$ (Tab. 2). The improvement in $\mathrm{M}$ units was also calculated, and it was statistically significant with a p-value of $<0.001$ (Tab. 3). Spectacle magnifiers were the most preferred ( $73 \mathrm{stu}-$

Table 1. Diagnosis of patients who benefited from low vision aids (LVA)

\begin{tabular}{|l|c|}
\hline Diagnosis & No. of patients $(\mathbf{n}=\mathbf{5 1 5})$ \\
\hline Microphthalmos & 47 \\
\hline Corneal opacity & 14 \\
\hline Coloboma & 12 \\
\hline Optic atrophy & 12 \\
\hline Pseudophakia & 11 \\
\hline Retinitis pigmentosa & 9 \\
\hline Aphakia & 6 \\
\hline Bupthalmos & 5 \\
\hline Cataract & 3 \\
\hline Leber's congenital amaurosis & 3 \\
\hline Albinism & 2 \\
\hline
\end{tabular}

Table 2. Line improvement and the number of patients involved

\begin{tabular}{|l|c|}
\hline Line improvement & No. of patients \\
\hline $0-1$ (clear) & 14 \\
\hline 1 & 33 \\
\hline 2 & 26 \\
\hline 3 & 20 \\
\hline 4 & 12 \\
\hline 5 & 15 \\
\hline 6 & 4 \\
\hline
\end{tabular}

Table 4. Functional vision assessment of the subjects

\begin{tabular}{|l|c|}
\hline Functional vision assessment & No. of subjects $(\mathbf{n}=\mathbf{5 1 5})$ \\
\hline Could see enough to walk around & $208(40.33 \%)$ \\
\hline Could recognize faces & $170(33 \%)$ \\
\hline Able to see print & $156(30.29 \%)$ \\
\hline Could not assess & $24(4.66 \%)$ \\
\hline
\end{tabular}

dents, $58.87 \%$ ), followed by magnifiers (50 students, $40.32 \%$ ) and glasses (1 student, $0.81 \%)$. Distance LVA, such as telescopes, were not determined in this experiment since they have limited applicability and are therefore more expensive than those used for close work. The assessment of day-to-day daily activities was used to determine functional vision. 208 (40.33\%) among 515 tested children could see well enough to move around unassisted (Tab. 4).

\section{DISCUSSION}

Because a considerable proportion of children in the school for the blind were born blind due to a globe defect, most students had no light perception. But severely visually impaired children could use their residual vision for functional purposes. Low vision aids can help them enhance their residual vision and perhaps relearn how to accomplish the impaired functional vision, which can help them resume daily activities like reading [5]. Low vision devices were prescribed to increase their residual vision for functional purposes.

A total of 270 children tested LVA as the rest had no light perception, and 124 children benefitted from LVA. Out of them, $110(40.74 \%)$ improved at least one line with LVA. The remaining 14 students $(5.18 \%)$ were dispensed LVA as their vision appeared clearer though the line improvement was not significant. In similar studies from London (UK), $35.7 \%$ of children improved with LVA [6]. In a cross-sectional study conducted in 13 special education schools in Delhi, high additional plus lenses were used as spectacle magni-

\begin{tabular}{|c|c|c|c|c|c|c|c|c|}
\hline & \multirow{3}{*}{$\begin{array}{c}\text { Mean visual } \\
\text { acuity (SD) } \\
\text { [logMAR] }\end{array}$} & \multicolumn{4}{|c|}{ Paired differences } & \multirow{3}{*}{$\mathbf{t}$} & \multirow{3}{*}{ df } & \multirow{3}{*}{$\begin{array}{c}\mathbf{p} \text {-value } \\
\text { (paired t-test) }\end{array}$} \\
\hline & & \multirow{2}{*}{$\begin{array}{c}\text { Mean } \\
\text { difference (SD) }\end{array}$} & \multirow{2}{*}{$\begin{array}{l}\text { Std. error } \\
\text { Mean }\end{array}$} & \multicolumn{2}{|c|}{$95 \% \mathrm{Cl}$ of the difference } & & & \\
\hline & & & & Lower & Upper & & & \\
\hline Without LVA & $3.20(1.87)$ & \multirow{2}{*}{$1.45(1.16)$} & \multirow{2}{*}{0.10} & \multirow{2}{*}{1.24} & \multirow{2}{*}{1.66} & \multirow{2}{*}{13.90} & \multirow{2}{*}{123} & \multirow{2}{*}{$<0.001$} \\
\hline With LVA & $1.76(1.23)$ & & & & & & & \\
\hline
\end{tabular}

$\mathrm{SD}$ — standard deviation; $\mathrm{Cl}$ — confidence interval 
fiers for near-related work, resulting in $20.3 \%$ of children improving by at least one WHO category of blindness [7]. However, in our study, we found that students with congenital anomalies like microphthalmos (35 students, 12.97\%) benefitted from spectacle magnifiers, and $(\mathrm{n}=15)$ benefitted with hand/stand magnifiers for near.

Early assessment and management go a long way in helping the children in blind schools. In our present study, there were five children with visual acuity between $6 / 6$ to $6 / 18$ and 20 children with cataract who were referred to the institute for management. These children might just have avoided special schools if they had received adequate treatment at a young age, which portraits volume about the level of awareness and rehabilitation in this region of the country. In our study, of 515 children, $24 \%$ improved with LVA for near. Most of the children had congenital anomalies. These results are in accordance with a study conducted in Nepal in 12 blind schools wherein $28.2 \%$ of children benefitted for near following a low vision assessment [8]. Blind schools and children studying in blind schools seem not to be prioritized. Proper evaluation at the appropriate time could help many children to learn in regular schools. A collaborative effort from ophthalmologists, optometrists, and schools for the blind with regular periodic check-ups could result in many children getting into integrated education, vocational training, and developing their potential to the fullest. This was also suggested by studies conducted by Wilkinson et al. [9] and De Carlo et al. [10] — ongoing, comprehensive multidisciplinary low vision services are necessary to help children with visual impairments meet their educational, vocational, and other needs.

\section{CONCLUSION}

Awareness of the potential value of low vision devices and their benefits in children studying in blind schools should be spread among ophthalmologists and eye care personnel. A thorough ophthalmic examination and evaluation of low vision and spectacles should be made mandatory before admission to schools. Then these schools will be able to cater to really blind children, while other low vision children can make it to regular schools.

\section{REFERENCES}

1. World Health Organization. Global initiative for the elimination of avoidable blindness. WHO/PBL/97.61. WHO, Geneva 1997.

2. Stelmack JA, Stelmack TR, Massof RW. Measuring low-vision rehabilitation outcomes with the NEI VFQ-25. Invest Ophthalmol Vis Sci. 2002; 43(9): 2859-2868, indexed in Pubmed: 12202503.

3. Coding instructions for the WHO/PBL eye examination record (version III). 1998. World Health Organization. https://apps.who.int/iris/ handle/10665/67896.

4. Coding Instructions. WHO/PBL eye examination record for children with blindness and low vision. ICEH, London .

5. Margrain TH. Helping blind and partially sighted people to read: the effectiveness of low vision aids. Br J Ophthalmol. 2000; 84(8): 919-921, doi: 10.1136/bjo.84.8.919, indexed in Pubmed: 10906105.

6. Rudduck G, Corcoran H, Davies K. Developing an integrated paediatric low vision service. Ophthalmic Physiol Opt. 2004; 24(4): 323-326, doi: 10.1111/j.1475-1313.2004.00208.x, indexed in Pubmed: 15228510.

7. Pal N, Titiyal JS, Tandon R, et al. Need for optical and low vision services for children in schools for the blind in North India. Indian $\mathrm{J}$ Ophthalmol. 2006; 54(3): 189-193, doi: 10.4103/0301-4738.27071, indexed in Pubmed: 16921217.

8. Kansakar I, Thapa HB, Salma KC, et al. Causes of vision impairment and assessment of need for low vision services for students of blind schools in Nepal. Kathmandu Univ Med J (KUMJ). 2009; 7(25): 44-49, doi: 10.3126/kumj.v7i1.1764, indexed in Pubmed: 19483452.

9. Wilkinson ME, Stewart IW, Trantham CS, et al. lowa's pediatric low vision services. J Am Optom Assoc. 1996; 67(7): 397-402, indexed in Pubmed: 8888865.

10. DeCarlo DK, Nowakowski R. Causes of visual impairment among children at the Alabama School for the Blind. J Am Optom Assoc. 1999; 70: 647-52, indexed in Pubmed: 10561923. 